Int. J. Electrochem. Sci., 11 (2016) 8204 - 8220,

\title{
Physical \& Electrochemical Properties of Green Synthesized Bunsenite NiO Nanoparticles via Callistemon Viminalis' Extracts
}

\author{
B.T. Sone $e^{1,2}$ X.G. Fuku ${ }^{1,2}$, M.Maaza $a^{1,2, *}$ \\ ${ }^{1}$ UNESCO-UNISA Africa Chair in Nanosciences/Nanotechnology, College of Graduate Studies, \\ University of South Africa, Muckleneuk ridge, P.O. Box 392, Pretoria, South Africa. \\ ${ }^{2}$ Nanosciences African Network (NANOAFNET)-Materials Research Department, iThemba LABS- \\ National Research Foundation, P.O. Box 722, Somerset West 7129, Western Cape Province, South \\ Africa. \\ *E-mail: sonebert@tlabs.ac.za, sonebert@gmail.com, maaza@tlabs.ac.za
}

doi: $10.20964 / 2016.10 .17$

Received: 28 January 2016 / Accepted: 18 July 2016 / Published: 6 September 2016

P-type Bunsenite $\mathrm{NiO}$ powders with an average crystallite size of $21 \mathrm{~nm}$ (as shown by $\mathrm{x}$-ray diffraction analysis) were produced via biosynthesis and heat treatment using aqueous extracts from red flowers of the plant, Callistemon viminalis. SEM showed that the $\mathrm{NiO}$ powders consisted of particles with sizes in the 20-35 nm range while XPS confirmed the formation of highly pure NiO. From Raman spectroscopy, strong 1 phonon vibrations at $507.4 \mathrm{~cm}^{-1}$ and the existence of a broadened 2-phonon band of reduced intensity at $1096 \mathrm{~cm}^{-1}$ confirmed that biosynthesized $\mathrm{NiO}$ powders were not only defect-rich/ rich in surface effects but were also nanosized with dimensions less than $100 \mathrm{~nm}$. Through UV-Vis-NIR spectroscopy, the optical band gap for an annealed spin-coated thin film of NiO obtained using the green coloured $\mathrm{Ni}^{2+}$-containing extract of Callistemon viminalis, was calculated to be 3.35 $\mathrm{eV}$. A cyclic voltammetric study of the $\mathrm{NiO}$ nanopowders on $\mathrm{Ni}$ showed the redox processes to be quasi-reversible with the films showing potential for pseudocapacitance and the specific capacitance of the $\mathrm{NiO}$ thin films on $\mathrm{Ni}$ being estimated at $101 \mathrm{~F} / \mathrm{g}$. Electrochemical impedance spectroscopy showed the associated redox processes to be primarily diffusion controlled at room temperature. Through these findings the use of natural plant extracts is hereby shown to be a cost-effective and environmentally friendly alternative to preparing Nickel oxide nanosized powders that can be of use in a variety of energy storage applications.

Keywords: Green synthesis, NiO nanoparticles, Raman spectroscopy, Electrochemical Impedance Spectroscopy, Pseudocapacitance.

\section{FULL TEXT}


(C) 2016 The Authors. Published by ESG (www.electrochemsci.org). This article is an open access article distributed under the terms and conditions of the Creative Commons Attribution license (http://creativecommons.org/licenses/by/4.0/). 